\title{
CIRCULATION IN THE FEET OF LEPROSY PATIENTS, WITH AND WITHOUT ULCERS
}

\author{
Dr. B. B. Gokhale
}

Hon. Dermatologist and Venereologist, Sassoon Hospitals, Poona

DR. S. M. VABLE

Dept. of Dermatology and Venereology, Sassoon Hospitals, Poona Suman ModaK

Staff Nurse, Dept. of Dermatology and Venereology, Sassoon Hospitals, Poona

\section{Introduction}

Trophic ulcers are quite a familiar sight in leprosy and are one of its most crippling complications. These lesions develop or continue to persist in spite of their local treatment along with the general treatment directed towards leprosy. A large number of factors are responsible for the causation and persistence of these lesions. While the importance of trauma and neurotrophic factors in their etiology has been well stressed, the impression of some of the workers is that an inadequate blood supply must also play an important role in their causation and in their persistence. Such circulatory disturbances could be due to abnormal impulses from the peripheral fibres of the autonomic nervous system, for this system is involved very early in leprosy (Khanolkar ${ }^{1}$ 1955); as also due to the involvement of blood vessels by a leprous process (Faget ${ }^{2}$ 1944).

Observation of skin temperatures has been used from the earliest times in the estimations of blood flow through a part. Surface thermometry is a simple but important procedure in the evaluation of peripheral circulation. Though this method is not very suitable for the study of transitory changes in circulation, it gives quite valuable information when these changes persist for several minutes.

The difference of temperature in the symmetrical areas is of clinical significance, but the difference of temperature in response to paralysis of vasomotor fibres is still more important. Such a paralysis can easily be achieved by a regional anaesthesia.

This allows the dilatation of the muscular coat of the blood vessels when not damaged by a serious pathological condition. Thus by this method it is possible to differentiate organic disease of the artery from functional vasomotor spasm, and also to forecast the results of sympathectomy.

\section{Material and Method}

During this study, four comparable groups of adults were studied, mostly males, aged between 18 to 50 years.

Group A Normal-Patients with normal healthy extremities and negative serological test for syphilis (S.T.S.) Most of these 
patients were given spinal anaesthesia for operations like hernia, hydrocele, etc.

Group B Patients with positive S.T.S. with clinically normal extremities. This group was included because one of the predominent features of syphilis is the occurrence of periarteritis and endarteritis.

Group C Leprosy patients with otherwise normal inferior extremities with normal muscular power, etc. (as judged by clinical examination).

Group D Leprosy patients with non-healing chronic ulcer on one of the feet (without any gross mutilation of feet and involvement of bones) with normal muscular power in both lower legs. These ulcers were usually existent for more than three months and did not yield to bed rest, aseptic dressings, and similar measures.

The leprosy patients under study were classified, their smears made, and records made of general details and of their ulcers.

The procedure adopted for the study of each patient was as follows.

A patient was made to lie down in a quiet draughtless room with trousers and underclothes removed. The oral temperature was noted and the blood piessure taken. After half an hour, the oral temperature was taken again and the temperatures of the lower third of the legs and dorsa of the feet were registered by the use of a thermocouple. Then $50 \mathrm{mg}$. of ephedrine were injected and five to ten minutes later an injection of $1.5 \mathrm{ml}$. of a spinal anaesthetic containing $0.5 \%$ nupercaine was given. The extremities were then tested for loss of sensation and power. After 25 and 35 minutes the temperatures in the lower third of the legs and the dorsa of the feet were recorded. (By experience it has been established that any changes in temperatures stabilise completely within 35 minutes of the spinal anaesthesia.)

The differences in temperature before and after the spinal anaesthesia have been recorded under the title 'Variation' in Tables No. I, II, III, and IV, as given in an Appendix to this paper.

\section{Results}

It is evident from Table I that there is no significant difference in the variations in temperatures in the normal feet and legs.

Similarly, it is indicated by Table II (Group B) and Table III (Group $C$ ) that there is no significant variation of the temperatures in the cases with positive S.T.S., and in leprosy cases without ulcer on the feet.

But Table IV (Group D) clearly shows that there is a significant variation in the temperatures between the ulcerated and nonulcerated feet, without any significant variation in the legs. 
It is interesting, as demonstrated by Table $\mathrm{V}$, that there is $\mathrm{no}$ significant difference between variations in the temperature in the normal foot of a leprosy patient having an ulcer on the other foot and in feet of a patient suffering from leprosy with otherwise normal lower extremities. But there is a significant variation between the normal subjects and the normal foot of leprosy patients with an ulcerated other foot.

\section{Discussion}

From the results recorded it seems that the variation in temperature, after the spinal anaesthesia, in the ulcerated feet of the leprosy patients is less as compared with the normal subjects (Table I-Group A), leprosy patients with normal feet (Table III-Group C), the other non-ulcerated foot of leprosy patients with ulcerated feet (Table IV_-Group D) and patients with positive serological test for syphilis (Table II-Group B). However, there is no significant variation in the lower third of the leg in any of these groups. This leads us to the conclusion that the arteries in the ulcerated feet of the leprosy patients are involved in the pathological process leading to deficiency in circulation. Table VI showing the range clearly brings out this point.

Thus, the arterial system in leprosy patients with ulcers on the feet is not the same as in normal subjects. This may be due to the pathological involvement of blood vessels, or it may be due to an inherent defect in the arterial circulation of the patients. This is illustrated by Case No. 8 of Table I. The interesting point is that the variation in temperature after the spinal anaesthesia is very small, in comparison to Cases No. 2, 5, 6, etc., of Table I. Thus it is possible that leprosy subjects with a similar inherent defective circulation could be predisposed to ulceration of feet under the conditions of stress and strain.

In the Cases Nos. 8 and 9 of Table IV, the variations are like those in normal subjects. These might be the cases which would improve after treatment directed towards vasodilatation, using sympatholytic vasodilators like Priscol (Ciba). But in Cases Nos. 2, 5 , 6, etc., of Table IV, the results with such drugs may not be encouraging, as the arterial system in these cases is inadequate. However, Hydergine (Sandoz) may be of some use because in addition to its sympatholytic effect it also has a direct action on the musculature of the blood vessels. This explains the variation in results after the therapeutic use of vasodilators (Gokhale, ${ }^{3}$ 1956; Watt Mane $y^{4}$, et al., 1958).

Therefore it can be concluded that there are definite circulatory deficiencies in the feet of leprosy patients with ulcers, some due to the leprotic involvement of blood vessels and others due to the inherent inadequacies of the circulatory system. 


\section{Summary}

Four groups of patients; (a) normal healthy individuals, $(b)$ normal individuals with positive serological test for syphilis, (c) leprosy patients without trophic ulcers on the feet and $(d)$ leprosy patients with non-healing chronic ulcer on one of the feet; were examined for the difference in variations in temperature in the lower third of the legs and dorsa of the feet before and after the administration of spinal anaesthesia.

This study indicates that the arterial circulation is defective in ulcerated feet in leprosy as judged by the significant difference in variation of temperatures before and after spinal anaesthesia.

The arterial circulatory deficiencies in ulcerated feet in leprosy could be due in some cases to the pathological involvement of the arterial system and in others to the inherent inadequacies of this system.

APPENDIX

TABLE No. I

Group A-Normals

Variation in temperature

(Variation in temperature (in centigrade)

\begin{tabular}{c|c|c|c|c}
\hline \multirow{2}{*}{$\begin{array}{c}\text { Serial } \\
\text { No. }\end{array}$} & \multicolumn{2}{|c|}{ Foot } & \multicolumn{2}{|c}{ LEG } \\
\cline { 2 - 4 } & Right & Left & Right & Left \\
\hline 1 & 3.6 & 2.0 & 1.6 & 1.9 \\
2 & 2.0 & 1.6 & 1.9 & 1.5 \\
3 & 3.2 & 3.0 & 1.0 & 2.0 \\
4 & 2.0 & 0.3 & 1.7 & 0.7 \\
5 & 3.0 & 3.4 & 1.6 & 2.1 \\
6 & 3.0 & 3.1 & 0.0 & 0.3 \\
7 & 1.4 & 1.0 & 0.9 & 0.6 \\
8 & 0.4 & 0.5 & 0.6 & 0.6 \\
9 & 4.6 & 3.4 & 0.1 & 0.1 \\
10 & 2.2 & 2.4 & 0.4 & 1.6 \\
11 & 3.2 & 3.6 & 1.0 & 0.6 \\
12 & 3.2 & 3.8 & 1.1 & 1.5 \\
13 & 1.5 & 1.4 & 0.3 & 0.6 \\
14 & 3.8 & 3.7 & 0.2 & 0.8 \\
15 & 4.5 & 4.4 & 0.2 & 0.8 \\
16 & 2.9 & 1.7 & 0.6 & 1.0 \\
\hline Mean & 2.8 & 2.3 & 0.8 & 1.04 \\
\hline
\end{tabular}

\section{NORMALS}

\begin{tabular}{|c|c|c|c|c|c|}
\hline Item & \multicolumn{2}{|c|}{ LEG } & \multicolumn{2}{|c|}{ FOOT } & $\mathrm{n}$ \\
\hline \multirow{2}{*}{ Mean } & Right & Left & Right & Left & $\mathrm{n}$ \\
\hline & 0.8 & 1.04 & 2.8 & 2.3 & 16 \\
\hline Value of ' $t$ ' & \multicolumn{2}{|c|}{$\begin{array}{c}\mathbf{R} \times \mathbf{X ~ L} \\
1.16 \\
\text { not significant }\end{array}$} & \multicolumn{2}{|c|}{$\begin{array}{c}\mathrm{R} \underset{1.08}{\mathrm{X}} \mathrm{L} \\
\text { not significant }\end{array}$} & $\begin{array}{c}\text { D,f. } \\
30\end{array}$ \\
\hline
\end{tabular}

In the normal sample the differences of means of the right and left legs or right and left feet are not significant. 
TABLE No. II

Group B-Patients with Positive S.T.S.

Variation in temperature (in centigrade)

\begin{tabular}{c|c|c|c|c}
\hline \multirow{2}{*}{$\begin{array}{c}\text { Serial } \\
\text { No. }\end{array}$} & \multicolumn{2}{|c|}{ FoOT } & \multicolumn{2}{c}{ LEG } \\
\cline { 2 - 4 } & Right & Left & Right & Left \\
\hline 1 & 3.1 & 3.8 & 0.9 & 1.7 \\
2 & 5.7 & 7.0 & 2.0 & 3.3 \\
3 & 3.2 & 2.6 & 1.4 & 0.9 \\
4 & 0.9 & 2.2 & 0.5 & 0.7 \\
5 & 4.0 & 4.0 & 2.6 & 2.8 \\
6 & 2.2 & 2.0 & 2.2 & 1.0 \\
7 & 1.6 & 1.0 & 0.8 & 2.2 \\
8 & 0.8 & 2.2 & 0.2 & 0.4 \\
9 & 3.6 & 2.3 & 1.6 & 1.0 \\
10 & 5.0 & 3.8 & 2.0 & 1.6 \\
11 & 3.2 & 2.7 & 1.7 & 1.70 \\
\hline Mean & 3.03 & 3.05 & 1.45 & \\
\hline
\end{tabular}

Patients with positive S.T.S.

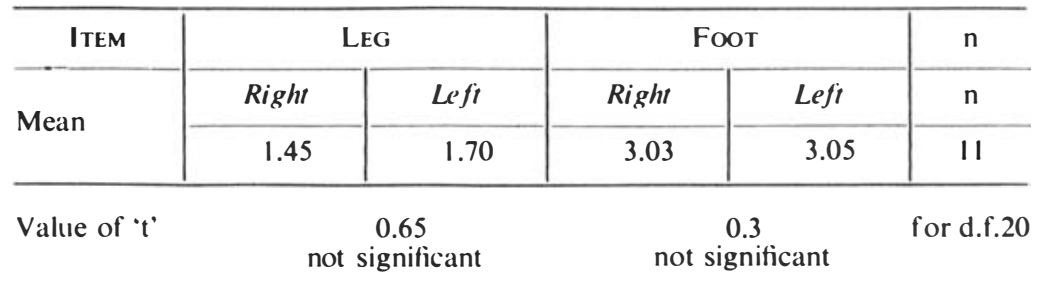

In the sample with positive S.T.S. the differences of means of the right and left foot and right and left leg are not significant at all.

TABLE No. III

Group C-Leprosy Patients without Ulcers on Feet Variation in temperature (in centigrade)

\begin{tabular}{c|c|c|c|c}
\hline \multirow{2}{*}{$\begin{array}{c}\text { Serial } \\
\text { No. }\end{array}$} & \multicolumn{2}{|c|}{ FoOT } & \multicolumn{2}{|c}{ LEG } \\
\cline { 2 - 4 } & Right & Left & Right & Left \\
\hline 1 & 3.3 & 4.1 & 1.5 & 2.2 \\
2 & 3.2 & 3.7 & 1.4 & 1.3 \\
3 & 0.2 & 0.9 & 0.2 & 0.3 \\
4 & 2.2 & 1.3 & 0.1 & 0.9 \\
5 & 1.3 & 1.8 & 1.4 & 2.5 \\
6 & 0.8 & 2.0 & 0.1 & 1.0 \\
7 & 2.7 & 1.5 & 1.8 & 1.3 \\
8 & 0.2 & 1.2 & 0.8 & 0.4 \\
9 & 0.8 & 1.0 & 0.7 & 0.2 \\
10 & 1.0 & 1.0 & 0.2 & 1.7 \\
11 & 1.0 & 1.0 & 0.2 & 1.7 \\
12 & 1.8 & 1.4 & 0.0 & 0.0 \\
13 & 3.8 & 3.0 & 2.6 & 2.6 \\
14 & 2.2 & 1.0 & 1.2 & 1.7 \\
15 & 0.2 & 1.2 & 0.8 & 0.6 \\
16 & 1.2 & 1.2 & 0.8 & 0.7 \\
\hline Mean. & 1.68 & 1.66 & 0.89 & 1.16 \\
\hline
\end{tabular}


Leprosy patients without ulcer

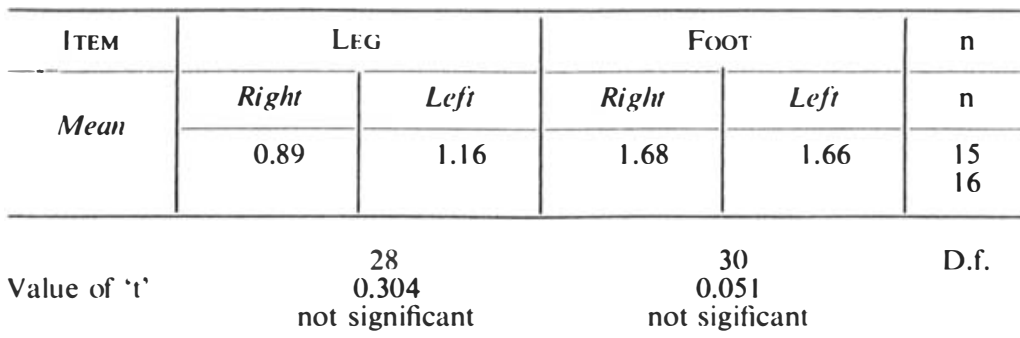

In the sample of leprosy patient without ulceration of feet, the difference in the means of the right and left leg or right and left foot are not significant.

TABLE No. IV

Group D-Leprosy Patients With Ulcer on one of the FeeI

Variation in temperature (in centigrade)

\begin{tabular}{c|c|c|c|c}
\hline \multirow{2}{*}{$\begin{array}{c}\text { Serial } \\
\text { No. }\end{array}$} & \multicolumn{2}{|c|}{ FoOT } & \multicolumn{2}{|c}{ LEG } \\
\cline { 2 - 3 } & Ulcerated & Non-ulcerated & Ulcerated & Non-ulcerated \\
\hline 1 & 0.5 & 3.2 & 0.0 & 0.0 \\
2 & 0.0 & 0.5 & 0.0 & 0.2 \\
3 & 0.0 & 1.0 & 0.2 & 1.2 \\
4 & 0.0 & 2.0 & 0.2 & 1.6 \\
5 & 0.4 & 0.2 & 0.0 & 0.5 \\
6 & 0.4 & 0.4 & 0.0 & 0.2 \\
7 & 1.2 & 0.6 & 1.7 & 1.6 \\
8 & 2.2 & 1.8 & 1.9 & 1.9 \\
9 & 1.6 & 2.0 & 2.4 & 1.6 \\
10 & 0.4 & 0.7 & 1.8 & 0.3 \\
11 & 1.0 & 0.7 & 1.1 & 0.4 \\
12 & 0.2 & 2.8 & 0.0 & 2.8 \\
13 & 0.4 & 1.0 & 0.4 & 0.6 \\
14 & 1.2 & 3.2 & 1.2 & 2.2 \\
\hline Mean & 0.68 & 1.44 & 0.71 & 1.09 \\
\hline
\end{tabular}

Leprosy patients-Ulcer on one foot

\begin{tabular}{c|c|c|c|c}
\hline \multirow{2}{*}{ ITEM } & \multicolumn{2}{|c|}{ LEG } & \multicolumn{2}{|c}{ FOOT } \\
\cline { 2 - 4 } & Ulcerated & Non-ulcerated & Ulcerated & Non-ulcerated \\
\cline { 2 - 4 } & 0.71 & 1.09 & 0.68 & 1.44 \\
\hline Value of ' $t$ ' & $\begin{array}{c}1.19 \\
\text { (d.f.26) } \\
\text { not significant }\end{array}$ & $\begin{array}{c}2.06 \\
\text { (d.f.26) }\end{array}$ \\
Significant (not highly)
\end{tabular}

From the above values it seems that the value of ' $t$ ' in case of feet with ulcer and without ulcer is found to be significant but in the case of the leg the value of ' $t$ ' is not significant. 
A-Normal (Table I).

TABLE No. $\vee$

C-Leprosy without ulcer (Table III).

D-Leprosy with ulcer (Table IV). Foot

I. Comparison between non-ulcerated foot of D and a foot of $C$.

\begin{tabular}{c|c|c}
\hline \multirow{2}{*}{ Mean } & $\mathrm{C}$ & $\mathrm{D}$ \\
\cline { 2 - 3 } & 1.67 & 1.44 \\
\hline
\end{tabular}

Value of ' $t$ '

0.59 (for d.f.28)

not significant

The two samples non-ulcerated foot of Leprosy patient with ulcer and a foot of Leprosy patient without ulcer are not significantly different.

2. Comparison between non-ulcerated foot of D (Leprosy with ulcer) and a foot of A (Normal).

\begin{tabular}{c|c|c}
\hline \multirow{2}{*}{ Mean } & $\mathrm{A}$ & $\mathrm{D}$ \\
\cline { 2 - 3 } & 2.56 & 1.44 \\
\hline
\end{tabular}

Value of ' $t$ '

2.78 (for d.f.28)

Value significant

This means, that, two samples-non-ulcerated foot of leprosy patient with ulcer and a foot of normal person-are significantly different. LEG

(But not very highly significant as in case of ulcerated foot.)

\begin{tabular}{l|c|c}
\hline \multirow{2}{*}{ 1. Mean } & $\mathrm{C}$ & $\mathrm{D}$ \\
\cline { 2 - 3 } & 1.1 & 1.09 \\
\hline
\end{tabular}

Value of ' $t$ '

0.032 (for d.f.27)

not significant at all

\begin{tabular}{l|c|c}
\hline \multirow{2}{*}{ 2. Mean } & $\mathrm{A}$ & $\mathrm{D}$ \\
\cline { 2 - 3 } & 0.93 & 1.09 \\
\hline
\end{tabular}

Value of ' $t$ '

0.61 (for d.f.28)

not significant at all.

From the above two results, it seems, in the case of the non-ulcerated leg, of leprosy patients with ulcer, there is no significant difference when compared with a leg of Leprosy patients without ulcer and Normal persons.

TABLE No. VI

Variation in temperature after spinal anaesthesia for range 0.0 to 1.0.

\begin{tabular}{l|l|l}
\hline Group & Description & \multicolumn{1}{|c}{ Results } \\
\hline A & Normals & $\begin{array}{l}\text { Only } 6.3 \% \text { of values lie in } \\
\text { the range } 0.0 \text { to } 1.0\end{array}$ \\
\hline C & $\begin{array}{l}\text { Leprosy } \\
\text { without ulcers }\end{array}$ & $\begin{array}{l}43.8 \% \text { values lie in the } \\
\text { same range } 0.0 \text { to } 1.0\end{array}$ \\
\hline D & $\begin{array}{l}\text { Leprosy } \\
\text { with ulcers }\end{array}$ & $\begin{array}{l}71.4 \% \text { values lie in the } \\
\text { same range } 0.0 \text { to } 1.0\end{array}$ \\
\hline
\end{tabular}

From the above it can be inferred that Group D always tends to have lower values than Groups $\mathrm{A}$ and $\mathrm{C}$ while Group $\mathrm{A}$ always tends to higher values. 


\section{Acknowledgements}

Our thanks are due to Superintendent, Kondhwa Leprosy Hospital, for permission to work in the hospital as also to Dr. S. V. Marathe and Mr. W. Jennings of the same hospital for their help and co-operation.

Thanks are also due to Civil Surgeon, Sassoon Hospitals, Poona, and colleagues at these hospitals, for their co-operation and encouragement, and kind thanks to Mrs. S. S. Pande for her help in statistical representation of data.

\section{References}

1. Khanolkar, V. R. Prospectives in Pathology of Leprosy. Indian J. of Med. Science, 9, 24 (Supplement).

2. FAGET, G. N. Bone Changes in Leprosy. Radiology, 42, I, 1944.

3. Goknale, B. B. Treatment of Trophic Ulcers of the Soles of the Feet in Leprosy with certain Hydrogenated Ergot Alkaloids. Dermatologica, 113, 1956, 142.

4. Watt Maney, W. A., Han-Weefong, Lo-Hong Ling. Trophic Ulceration of the Foot Treated with Intra-arterial Hydergine. Internat. J. of Leprosy, 26, $1958,115$. 